\title{
Morphological and functional characteristics of cryopreserved multipotent mesenchymal stromal cells from bone marrow, adipose tissue and tendons
}

\author{
Volkova N. A., Yukhta M. S., Goltsev A. N. \\ Institute for Problems of Cryobiology and Cryomedicine NAS of Ukraine, Kharkiv, Ukraine \\ e-mail: volkovanatali2006@yandex.ua
}

\section{ABSTRACT}

Current approaches to cryopreservation of multipotent stem cells from various sources are aimed at maximum keeping of all original characteristics of the cell product for further use in experimental or clinical studies.

THE AIM OF RESEARCH was to compare morphological and functional properties of cryopreserved multipotent mesenchymal stromal cells (MMSCs) from bone marrow, adipose tissue and tendons.

MATERIALS AND METHODS. MMSCs cultures were obtained from rat bone marrow, adipose tissue and tendons according standard methods. The cells were cryopreserved under protection of $10 \%$ DMSO and $20 \% \mathrm{FBS}$ at cooling rate $1{ }^{\circ} \mathrm{C} / \mathrm{min}$ down to $-80^{\circ} \mathrm{C}$ followed by transfer into liquid nitrogen. The cell membrane integrity, immunophenotype, colony-forming activity, proliferative properties (MTT assay), directed differentiation and type I collagen synthesis were evaluated.

RESULTS. The studied cryopreserved cell cultures derived from bone marrow, tendons and adipose tissue had high cell membrane integrity, colony-forming ability and proliferation as well as the ability to directed adipogenic and chondrogenic differentiation. The analysis of immunophenotype showed that the tested cryopreserved MMSCS was characterized by high levels of CD44, CD90, CD105 and CD73 expression ( $\geq 90 \%$ ) and low expression of hematopoietic marker CD45 ( $\leq 1 \%)$. Cryopreserved bone marrow MMSCs were characterized by a large number of cells that produced type I collagen as compared to culture derived from adipose tissue and tendons.

CONCLUSIONS. Cell cultures obtained from all studied sources have immunophenotype of mesenchymal precursors. The MMSCs of tendon tissue exhibit a greater colony-forming capacity and proliferation, and lower potential for directed adipogenic differentiation, than MMSCs from bone marrow and adipose tissue.

KEYWORDS: multipotent mesenchymal stromal cells; cryopreservation; colony-forming unit; cell differentiation

Obtaining, cultivation and cryopreservation of mesenchymal stromal cells is the basic procedures for cellular products used in regenerative medicine for the treatment of many diseases. Today mesenchymal stem cells are isolated from different sources, such as bone marrow, adipose tissue, umbilical cord blood, skin and others [1-5]. Due to its properties, multipotent mesenchymal stromal cells (MMSCs) are the subject of special attention because they are able to differentiate into specialized cells that support hematopoiesis and have trophic and immunomodulatory properties owing to their ability to secretion of cytokines, chemokines and growth factors. Overall, these properties make them one of the main candidates for biotechnology and tissue engineering development [1, 6, 7].

In 2006 the International Society for Cellular Therapy (ISCT) proposed basic criteria for determining MMSCs, namely adhesive fibroblastlike cells that are CD105, CD73, CD90 positive and CD45, CD34, CD14 or CD11b, CD19 or CD79a and HLA-DR negative, capable of directed differentiation into adipogenic, osteogenic and chondrogenic lineages. This minimum set of phenotypic criteria for MMSCs identification is not associated with their origin [1, 2, 4, 8-10]. Cultivation, differentiation and cryopreservation of MMSCs in vitro can alter the natural cell properties [11-13]. Therefore, to create new biotechnology-based products, it is 
important to use cells which retains stable morphological and functional properties.

Today, bone marrow is studied well enough as a source of stem cell from adult donors. Considering that bone marrow MMSCs are multipotent and able to proliferate in vitro, they quickly became used in early clinical studies $[14,15,16]$. MMSCs constitute only a small percentage of bone marrow cells $(0.01-0.001 \%$ of nucleated cells), their differentiation potential and number have a negative correlation with the age. Later MMSCs with similar immunophenotype were also obtained from other tissues.

An alternative source of MMSCs for cell therapy is adipose tissue where they can be obtained through minimally invasive methods in much larger amounts compared to bone marrow. These cells can be easily isolated from lipoaspirate and are able to differentiate into osteogenic, adipogenic, myogenic, neurogenic and chondrogenic direction $[1,17,18]$.

At present, stem cells from tendons are examined in vivo and in vitro in few researches. There have been studied proliferative potential and ability to multilinear differentiation of progenitor cells from tendon tissue isolated from a human hamstring $[7,9]$. This observation has helped to understand the pathophysiology of tendon tissue and contributed to the search for new potential tools for the treatment of tendon injuries.

Transplantation of autologous or allogeneic MMSCs is a method of cell therapy and has significant perspectives in the treatment of many human diseases. The involvement of modern cultivation and cryopreservation technologies allow to receive a supply of stem and specialized cells with their subsequent long-term storage at low temperatures. This allows to transport cryovials readily and thaw cells just before therapeutic application. In order to provide the baselines for further research in the field of regenerative medicine, there have been analyzed rat MMSCs derived from bone marrow and two alternative sources of adipose tissue and tendons. This study presents a comparison of cryopreserved MMSCs to create an experimental evaluation system for choice of the optimal source of cells for the treatment of musculoskeletal tissue injuries.

The purpose of the study was a comparative assessment of some morphological characteristics of cryopreserved MMSCs obtained from bone marrow, adipose tissue and tendons.

\section{MATERIALS AND METHODS}

Obtaining and cultivation of MMSCs. Bone marrow cells were isolated from rat femurs by flushing of diaphyses with Hanks balanced salt solution - HBSS (PAA, Austria), followed by passing the suspension through small-gauge needles. The next stage included centrifugation at $834 \mathrm{~g}$ for $5 \mathrm{~min}$.

Primary suspension cells from adipose and tendon rat tissue was obtained by enzymatic treatment of biopsy specimens. For this pieces weighing $75 \pm 3 \mathrm{mg}$ were washed with HBSS containing $150 \mu \mathrm{g} / \mathrm{mL}$ gentamicin (Farmak, Ukraine) and incubated in $1.5 \mathrm{mg} / \mathrm{mL}$ collagenase type II solution (PanEko, Russia) at $37^{\circ} \mathrm{C}$ for 18 hours. The cells were isolated from pieces by resuspending followed by centrifugation at $834 \mathrm{~g}$ for $3 \mathrm{~min}$.

The resulting cell suspensions were plated in $25 \mathrm{~cm}^{2}$ culture flasks (PAA, Austria) at a density of $10^{3}$ cells $/ \mathrm{cm}^{2}$ [19]. The culture medium in all cases contained the culture medium IMDM (PAA, Austria), $10 \%$ fetal bovine serum (HyClone, USA), $150 \mu \mathrm{g} / \mathrm{mL}$ kanamycin (Farmak, Ukraine) and $5 \mu \mathrm{g} / \mathrm{mL}$ amphotericin B (PAA, Austria). The medium was changed every three days. In the study, we used standard culture conditions in $\mathrm{CO}_{2}$-incubator (Sanyo, Japan) at $37{ }^{\circ} \mathrm{C}$ and $5 \% \mathrm{CO}_{2}$ atmosphere. Subcultivation was carried out upon reaching confluency. Cell growth was determined under light microscope (LOMO, Russia).

MMSCs cryopreservation. Cryopreservation was performed in $1 \mathrm{ml}$ cryovials (Nunc, USA) under the protection of $10 \%$ DMSO (PanEko, Russia) with $20 \%$ fetal bovine serum. Cryoprotectants solution was prepared in IMDM medium with kanamycin $150 \mu \mathrm{g} / \mathrm{mL}$. Cooling of samples was performed using the programmed freezer ZPM-1 (Otel, Ukraine). Cooling rate was $1^{\circ} \mathrm{C} / \mathrm{min}$ to $-80^{\circ} \mathrm{C}$, followed by storage in liquid nitrogen [20]. Cryopreserved MMSCs thawing was performed in a water bath at $40{ }^{\circ} \mathrm{C}$ until the liquid phase. Removal of cryoprotectant was performed by adding 1:9 HBSS, followed by centrifugation at $834 \mathrm{~g}$ for $5 \mathrm{~min}$. At cultivation the studied cells after cryopreservation, we used the same conditions as for the primary cultures. The integrity of cell membranes was evaluated by a trypan blue (Sigma, USA) dye exclusion.

MIMSCs immunophenotyping. For immunophenotypic analysis MMSCs after freezing and thawing were stained with mouse anti-human CD45-FITC, CD44-FITC, CD73-FITC, CD90-FITC, CD105-PE monoclonal antibodies (BD Biosciences, USA) according to the manufacturer's instructions. Measurements were performed on flow cytometer BD FACSCalibur (Becton Dickinson, USA). Data were analyzed using Win MDI v.2.8.

Assessment of MMSCs colony-forming capacity. Cloning efficiency was determined by counting the colonies containing at least 30 cells, and calculated as a percentage of colony forming fibroblast units (CFU-F) per $1 \cdot 10^{6}$ cells. Cells were seeded in 6 -well plates at low density by limiting dilution (start with a seeding density of $100 \mathrm{cells} / \mathrm{cm}^{2}$ to $15 \mathrm{cells} / \mathrm{cm}^{2}$ ) and cultured in IMDM medium supplemented with $20 \%$ fetal bovine serum for 14 days. Then the cells were fixed with $4 \%$ paraformaldehyde solution followed by Romanovsky-Giemsa azure II-eosin staining for 10 $\mathrm{min}$ at room temperature. The number of colonies, their size and average number of cells per colony were measured [17].

Colorimetric MTT assay for MMSCs proliferation. The number of viable cells in the MMSCs' cultures was determined by MTT test (Sigma, USA) on 1, 3, 7 and 10 days of cultivation [21]. Measurement of the optical density was performed on photocolorimeter KFK-2 UHL42 (Russia) at a wavelength of $540 \mathrm{~nm}$.

Immunohistochemical study of type I collagen. Staining for collagen type I was performed using monoclonal antibodies to COL-1 (SigmaAldrich, USA) in dilution 1:2000 and CFTM488A (Sigma-Aldrich, USA) according to the manufacturer's instructions. The cells nuclei were additionally stained with DAPI (Sigma, USA) at a concentration of $1 \mu \mathrm{g} /$ $\mathrm{mL}$ for $30 \mathrm{~min}$. Fluorescent microscopy of MMSCs was performed using confocal scanning microscope LSM 510 Meta (Carl Zeiss, Germany).

Directed adipogenic differentiation. For directed differentiation into adipogenic lineage standard nutrient medium in cultures after reaching confluency was changed for differentiation medium consisting of IMDM, $1 \%$ fetal bovine serum, $10^{-7} \mathrm{M}$ dexamethasone, $10^{-9} \mathrm{M}$ insulin (all - $P A A$, Austria). Further cultivation was carried out for 3 weeks changing medium twice a week. To confirm the differentiation, the cells were stained with Sudan IV (Fluka, Germany) and under a light microscope we counted the number of cells with lipid droplets (orange stain), calculating the percentage of the total number of cells. The control for spontaneous differentiation were cells cultured without specific inductors.

Directed chondrogenic differentiation. For directed differentiation in chondrogenic lineage, standard nutrient medium in cultures after reaching confluency was changed for differentiation medium consisting of IMDM, $10^{-5}$ ascorbate-2-phosphate (PAA, Austria), $10 \mathrm{ng} / \mathrm{ml}$ TGF- $\beta$ (Sigma, USA). Further cultivation was carried out for 3 weeks changing medium twice a week. To confirm the differentiation, the cultures were stained with Toludine blue (Fluka, Germany) and we counted the number of cells with proteoglycans in the extracellular matrix (blue stain). Number of differentiated cells was counted under a light microscope and we calculated the percentage of the total number of cells. The control for spontaneous differentiation was cells cultured without specific inductors [22]. 


\begin{tabular}{|c|c|c|c|c|c|c|}
\hline \multirow{2}{*}{ MMSCs SOURCE } & \multicolumn{5}{|c|}{ EXPRESSION LEVEL, \% } & $\begin{array}{l}\text { Table 1. Immunophenotype } \\
\text { of cryopreserved MMSCs from }\end{array}$ \\
\hline & CD44 & CD45 & CD73 & CD90 & CD105 & bone marrow, adipose tissue \\
\hline Bone marrow & $97.7 \pm 0.2$ & $1.1 \pm 0.1$ & $97.3 \pm 0.8$ & $91.5 \pm 1.2$ & $95.4 \pm 0.4$ & and tendons $(n=6, M \pm m)$. \\
\hline Adipose tissue & $93.4 \pm 0.6$ & $0.8 \pm 0.3$ & $90.7 \pm 0.5$ & $89.2 \pm 0.9$ & $95.1 \pm 0.8$ & \\
\hline Tendon tissue & $96.1 \pm 0.3$ & $0.6 \pm 0.1$ & $89.5 \pm 1.1$ & $92.1 \pm 0.7$ & $94.4 \pm 0.6$ & \\
\hline
\end{tabular}

Statistical analysis. Testing of the normality was carried out using common test for asymmetry and kurtosis. At the normal distribution of variables, reliability of differences between groups was evaluated using Student's t-test. Differences is significant at $p \leq 0.05$. Analysis was performed using MS Excel (Microsoft, USA) and Statistica 8 (StatSoft Inc., USA) software.

\section{RESULTS AND DISCUSSION}

The first step was to study the integrity of cell membranes after cryopreservation using trypan blue exclusion test. Bone marrow MMSCs after cryopreservation-thawing had $78.5 \pm 6.2 \%$ cells with intact membrane that is 1.24-times lower than the corresponding value in primary cultures prior to freezing $(95.2 \pm 4.5 \%)$. The viability of cryopreserved adipose MMSCs was reduced to 1.18-times relative to the initial cells $(97.4 \pm 5.8$ $\%$ ) and amounted to $80.2 \pm 4.4 \%$. Reducing of viable cells percentage was also observed in tendon MMSCs after cryopreservation $79.3 \pm 3.2$, namely 1.19 -times in relation to the native sample $(94.4 \pm 3.4 \%)$.

MMSCs populations derived from bone marrow, adipose tissue and tendons were characterized by immunophenotype presented in Table 1. Cryopreserved cells revealed typical mesenchymal phenotype with high expression ( $\geq 90 \%$ ) of CD44, CD90, CD105, CD73 and low expression $(\leq 1 \%)$ of hematopoietic marker CD45, which corresponded immunophenotype of respective cultures before cryopreservation (data are not shown).

The cultivation of cells at low density can detect fibroblast colonyforming units, which are the earliest stromal cells precursors $[5,7]$ Using cell seeding 10-15 cells/ $\mathrm{cm}^{2}$ we observed colonies that formed with the frequency of 3-4 per 100,000 seeded cells. The results are presented in Fig. 1.

In the study of CFU-F, obtained from various sources, was detected colonies of several types that varied by the number of cells and their size. Colonies were divided into three types: compact with linear dimensions 4.8-7.2 $\mathrm{mm}$ in diameter, diffuse - 2.8-6.4 mm and mixed - 1.5-3.8 mm In the analysis we include wells containing all types of colonies, which consisted of more than 30 cells $[5,7]$.

The analysis of the colonies proportion revealed significant differences, namely the greatest clonogenic potential observed in tendon tissue MMSCs, where we observed compact and mixed colonies. Diffuse colonies were typical for adipose tissue MMSCs. Research of bone marrow MMSCs also showed the presence of compact and mixed colonies, but their number was significantly lower relative to tendon tissue. Significant difference in the number of CFU-F between adipose tissue and bone marrow was not found (Fig. 1).

The next stage was the study of proliferative characteristics of cryopreserved MMSCs from bone marrow, adipose tissues and tendons. Cells attached to the plastic and formed clusters of $10-15$ cells on 5-7thday of observation. Growth dynamics of studied cultures was similar, but increase of cells was significantly higher in the tendon MMSCs. On the day 3 of adipose tissue MMSCs cultivation, cell proliferation was 3.2 higher times, for tendon-derived -2.8 times as compared to bone marrow cells. On the $7^{\text {th }}$ and $10^{\text {th }}$ day of cultivation, the value of MTT-test for adipose MMSCs was higher 2.1 and 1.5 times, for tendon-derived cells -3.2 and 1.8 times respectively, as compared to bone marrow MMSCs (Fig. 2). In the following passages, cell cultures had a higher ability to proliferate

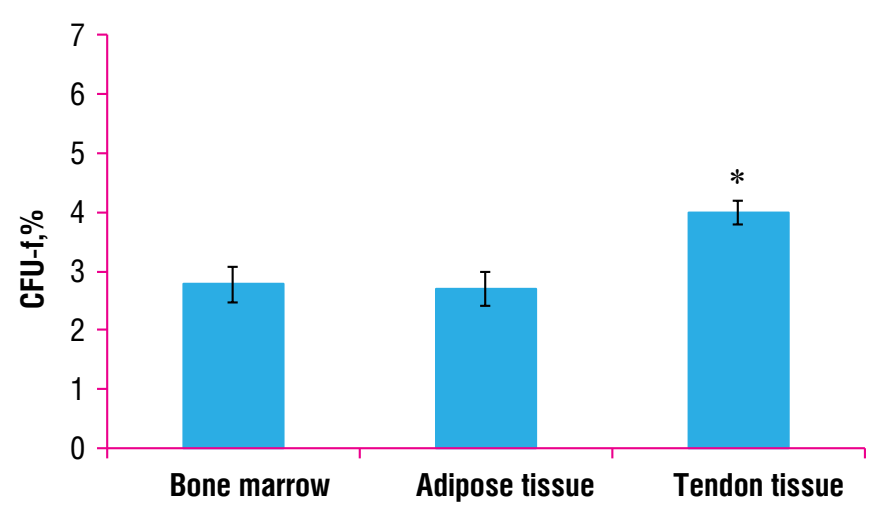

Fig. 1. The relative number of fibroblast colony-forming cells (CFU-F) in cultures of cryopreserved MMSCs from bone marrow, adipose tissues and tendons $(n=6, M \pm m)$.

Note: * - differences is significant in comparison with the corresponding value of bone marrow MMSCs, $p \leq 0.05$

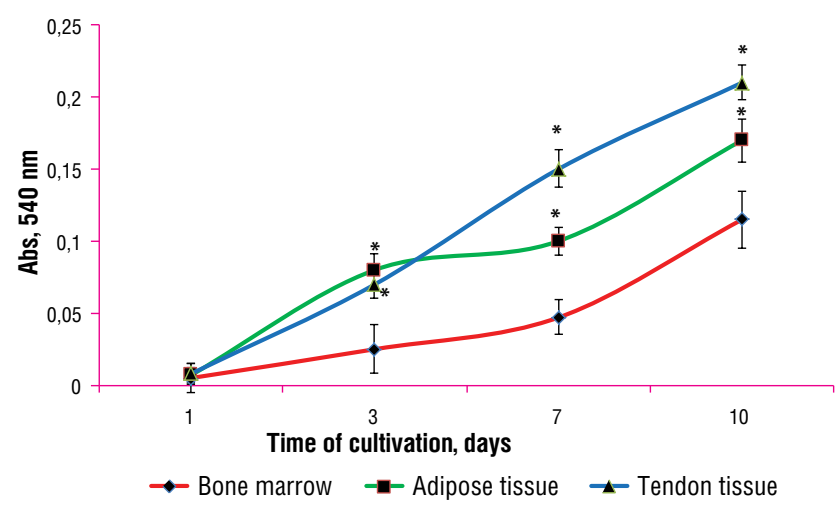

A

Fig. 2. Optical density at colorimetric MTT-assay in dynamics of cultivation of cryopreserved MMSCs from bone marrow, adipose tissue and tendons $(n=6, M \pm m)$

Note: * - differences is significant in comparison with the corresponding value of bone marrow MMSCs, $p \leq 0.05$

than immediately after thawing. This phenomenon is probably due to, on the one hand, inhibition of proliferative activity after cryopreservation and, on the other hand, adaptation of cells to culture conditions [20, 23-25].

Morphological characteristics of the studied cells and their ability to collagen type I production are shown in Fig. 3. Cryopreserved bone marrow MMSCs were characterized by the presence of spindle-shaped and sail-shaped cells, which $89.6 \pm 2.7 \%$ were positively stained for type I collagen. Adipose MMSCs were presented by sail-, star- and spindleshaped cells' types. Tendon-derived MMSCs had a spindle- and triangularshape with homogeneous cytoplasm density. The relative number of cells that produced collagen type I, in cultures of adipose-derived and tendonderived MMSCs was less than in bone marrow MMSCs and amounted to $52.6 \pm 2.1 \%$ and $63.4 \pm 2.5 \%$ respectively. 

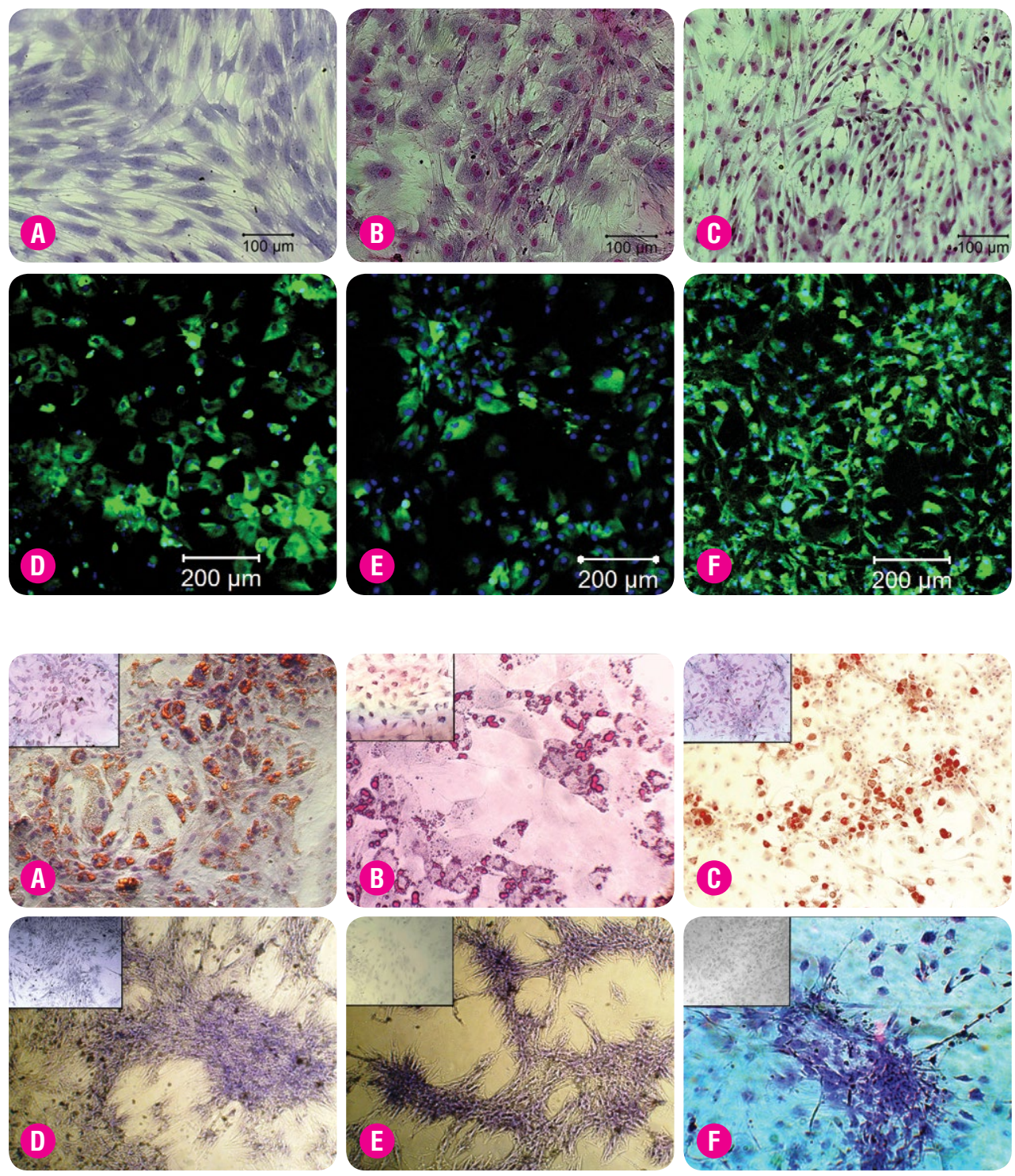

Fig. 3 Microphotographs of bone marrow $(A, D)$, adipose tissue $(B, E)$ and tendon-derived (C, F) MMSCs on the 10th day of cultivation. Light microscopy $(A-C)$, azure II-eosin staining. Fluorescent microscopy (D-F), immunofluorescent staining for collagen type I (green), nuclei stained with DAPI (blue).
Ability to directed adipogenic and chondrogenic differentiation of cryopreserved bone marrow, adipose tissue and tendon-derived MMSCs are presented in Table 2 and Figure 4.

The first signs of adipogenic differentiation, evidenced in changing the morphology of cells (roundness, cytoplasm granularity), were observed on $5-7^{\text {th }}$ day in bone marrow and adipose tissue MMSCs and on 8-10 day in tendon-derived MMSCs. Cytochemical staining of bone marrow and adipose tissue MMSCs cultures with dye Sudan IV on $21^{\text {st }}$ day after the initiation of adipocyte differentiation revealed the presence of orange lipid droplets in the cytoplasm of more than $54.7 \pm 6.2 \%$ and $62.7 \pm 5.3$ $\%$ of cells, respectively. In tendon-derived MMSCs cultures the number of cells with features of adipogenic differentiation amounted to $20.6 \pm 7.3 \%$.

In the study of directed chondrogenic differentiation, first signs of the change in the morphology of bone marrow and adipose-derived MMSCs were observed on $3-4^{\text {th }}$ days of cultivation and on the $5-6^{\text {th }}$ day in MMSCs from tendons. Since the $8^{\text {th }}$ day of chondrogenic differentiation in cultures, we observed areas of high cells concentration. In further observations, cell density increased and on the 21st day there was creation of formed structures with large amount of extracellular matrix, which was confirmed by their staining with Toluidine blue for the proteoglycans. The total percentage of differentiated cells in chondrogenic direction of bone marrow MMSCs was $70.3 \pm 5.6 \%$, adipose tissue MMSCs $-68.7 \pm 7.1 \%$ and tendon-derived MMSCs $-68.2 \pm 4.8 \%$.
Thus, apart from bone marrow and adipose tissue, which are the most common source of stem cells, an alternative source can be tendons. The results of the study can be used to create a cryobank of advanced stromal cell lines with their subsequent application for the needs of biotechnology and cell therapy of musculoskeletal system injuries. The research of morphological and functional characteristics of the MMSCs cultures showed that their cryopreservation using low cooling rate $1{ }^{\circ} \mathrm{C} / \mathrm{min}$ to $-80{ }^{\circ} \mathrm{C}$ and cryopreservation medium (10\% DMSO and $20 \%$ fetal bovine serum) can maintain the integrity of cell membranes, immunophenotype, ability to colony formation, proliferation, synthesis of collagen type I and directed differentiation regardless of their source.

However, a comparative analysis of these characteristics at the initial stages of cultivation found that bone marrow and adipose tissue MMSCs have slow proliferation, low capacity for colony formation and high potential to adipogenic and chondrogenic differentiation. Tendonderived MMSCs under the same cryopreservation conditions have a greater potential for proliferation, colony formation and lower capacity for directed differentiation in adipogenic direction than other studied cell types.

Summing up, low proliferative activity of cryopreserved bone marrow MMSCs, is combined with a high relative number of cells that produced type I collagen. At the same time, tendon- and adipose-derived MMSCs kept under similar cryopreservation conditions show a higher capacity to 


\begin{tabular}{|c|c|c|c|c|c|}
\hline \multirow{2}{*}{ MMSCs SOURCE } & \multicolumn{2}{|c|}{$\begin{array}{l}\text { ADIPOGENIC DIFFERENTIATION, } \\
\text { POSITIVE STAINING WITH SUDAN IV }\end{array}$} & \multicolumn{2}{|c|}{$\begin{array}{l}\text { CHONDROGENIC DIFFERENTIATION, POSITIVE } \\
\text { STAINING WITH TOLUIDINE BLUE }\end{array}$} & $\begin{array}{l}\text { Table } 2 \text {. Ability } \\
\text { to adipogenic }\end{array}$ \\
\hline & $\begin{array}{l}\text { Spontaneous } \\
\text { differentiation }\end{array}$ & $\begin{array}{l}\text { Induced } \\
\text { differentiation }\end{array}$ & $\begin{array}{l}\text { Spontaneous } \\
\text { differentiation }\end{array}$ & $\begin{array}{l}\text { Induced } \\
\text { differentiation }\end{array}$ & and chondrogenic \\
\hline Bone marrow & - & + & - & + & adipose tissue and \\
\hline Adipose tissue & \pm & + & - & + & tendon-derived \\
\hline Tendons & - & \pm & - & + & . \\
\hline
\end{tabular}

Notes: «+»-differentiation of more than 50 \% cells; « \pm - differentiation of less than $50 \%$ cells; «-» - no differentiation.

proliferation and relatively low number of type I collagen-producing cells, compared to bone marrow MMSCs.

Despite the fact that this study has no direct clinical relevance, it should be considered as an attempt to determine the optimal source for potential use of MMSCs in regenerative medicine. Although in most cases mechanisms through which the transplanted cells stimulate tissue regeneration, currently remain poorly understood, the results of this study contribute to their understanding and may be useful in designing therapeutic strategies for different musculoskeletal system diseases.

\section{CONCLUSION}

1. Cryopreserved cells obtained from bone marrow, adipose tissue and tendons manifest certain immunophenotypic characteristic of MMSCs, high membrane integrity, colony-forming capacity and proliferation, as well as the ability to adipogenic and chondrogenic directed differentiation.

2. Proliferative and colony forming capacity of MMSCs cultures from bone marrow and adipose tissue after cryopreservation was lower than in tendon-derived MMSCs.

3. Cryopreserved bone marrow MMSCs were characterized by a large number of cells than produced collagen type I, compared with cultures obtained from the tendons and adipose tissue.

\section{REFERENCES}

1. Dominici M, Le Blanc K, Mueller I, et al. Minimal criteria for defining multipotent mesenchymal stromal cells. The International Society for Cellular Therapy position statement Cytotherapy. 2006; 8(4):315-17.

2. Baksh D, Yao R, Tuan R. Comparison of proliferative and multilineage differentiation potential of human mesenchymal stem cells derived from umbilical cord and bone marrow. Stem cells. 2007; 25(4):1384-92.

3. Busser H, Najar M, Raicevic G, et al. Isolation and Characterization of Human Mesenchymal Stromal Cell Subpopulations: Comparison of Bone Marrow and Adipose Tissue. Stem cells and development. 2015; 24(18):2142-57.

4. Díaz-Prado S, Muiños-López E, Hermida-Gómez T, et al. Multilineage differentiation potential of cells isolated from the human amniotic membrane. J Cell Biochem. 2010; 111(4):846-57.

5. Hegyi B, Sagi1 B, Kovacs J. Identical, similar or different? Learning about immunomodulatory function of mesenchymal stem cells isolated from various mouse tissues: bone marrow, spleen, thymus and aorta wall. Int Immunology. 2010; 22(7):551-59.

6. Suzdaltsev G, Burunova VV, Vakhrushev IB. Sravnenie sposobnosti k differentsirovke v tkani mezodermal'nogo proiskhozhdeniya mezenkhimal'nykh kletok cheloveka, vydelennykh iz raznykh istochnikov [Comparison of ability to differentiate into tissue of mesodermal origin human mesenchymal cells isolated from different sources]. Kletochnye tekhnologii v biologii i meditsine - Cell Technologies in Biology and Medicine. 2007; 1:3-10. [in Russian]

7. Stanco D, Vigant M, Perucca $C$, et al. In vitro characterization of stem/progenitor cells from semitendinosus and gracilis tendons as a possible new tool for cell-based therapy for tendon disorders. Joints. 2014; 2(4):159-68.

8. Angelo PC, Ferreira AC, Fonseca VD, et al. Cryopreservation does not alter karyotype, multipotency, or NANOG/SOX2 gene expression of amniotic fluid mesenchymal stem cells. Genet Mol Res. 2012; 11(2):1002-12.

9. Rui YF, Lui PP, Li G, et al. Isolation and characterization of multipotent rat tendon-derived stem cells. Tissue Eng Part A. 2010; 16:1549-58.

10. Pittenger MF, Mackay AM, Beck SC, et al. Multilineage potential of adult human mesenchymal stem cells. Science. 1999; 284(2):143-47.

11. Pogozhykh D, Prokopyuk V, Pogozhykh O, et al. Influence of factors of cryopreservation and hypothermic storage on survival and functional parameters of multipotent stromal cells of placental origin. PLoS One. 2015; 2(10):0139834.

12. Volk SW, Wang $Y$, Hankenson KD. Effects of donor characteristics and ex vivo expansion on canine mesenchymal stem cell properties: implications for msc-based therapies. Cell Transplant. 2012; 21(10):2189-200. doi:10.3727/096368912X636821

13. Hagmann S, Moradi B, Frank S, et al. Different culture media affect growth characteristics, surface marker distribution and chondrogenic differentiation of human bone marrow-derived mesenchymal stromal cells. BMC Musculoskelet Disord. 2013; 14:223.

14. Giordano A, Galderisi U, Marino IR. From the laboratory bench to the patient's bedside: An update on clinical trials with mesenchymal stem cells. Journal of Cellular Physiology. 2007; 211(1):27-35.

15. Barry FP, Murphy JM. Mesenchymal stem cells: clinical applications and biological characterization. The International Journal of Biochemistry \& Cell Biology. 2004; 36(4):568-84 
16. Garcia-OImo D, Garcia-Arranz M, Herreros D, et al. A phase I clinical trial of the treatment of crohn's fistula by adipose mesenchymal stem cell transplantation. Dis Colon Rectum. 2005; 48(7):1416-23.

17. Rogulska OYu, Revenko O, Petrenko YuA, Petrenko AYu. Proliferativno-differentsirovochnyy potentsial mul'tipotentnykh mezenkhimal'nykh stromal'nykh kletok zhirovoy tkani pri kul'tivirovanii v prisutstvii trombotsitarnogo lizata [Proliferative and differentiation potential of adipose tissue-derived mesenchymal stromal cells in the presence of platelet lysate]. Geny i kletki - Genes and Cells. 2014; 9(2):63-67. [in Russian]

18. Gonda $K$, Shigeura $T$, Sato $T$, et al. Preserved proliferative capacity and multipotency of human adipose-derived stem cells after long-term cryopreservation. Plast Reconstr Surg. 2008; 121(2):401-10.

19. Adams RLP. Cell culture for biochemists. Amsterdam and New York: Elsevier, 1980. $292 \mathrm{pp}$

20. Volkova NA, Goltsev AN. Cryopreservation effect on proliferation and differentiation potential of cultured chorion cells. CryoLetters. 2015; 36(1):25-29.

21. Mossman T. Rapid colorimetric assay for cellular growth and survival: application to proliferation and cytotoxicity assays. J Immunol Methods. 1983; 65:55-63.

22. Pratheesh MD, Gade NE, Katiyar AN, et al. Isolation, culture and characterization of caprine mesenchymal stem cells derived from amniotic fluid. Isolation Res Vet Sci. 2013; 94:313-319.

23. Volkova NO. Doslidzhennya morfofunktsional'nikh kharakteristik kriokonservovanikh kul'tur klitin stromal'nogo pokhodzhennya [Study of morphological characteristics of cryopreserved cell cultures of stromal origin]. Problemy kriobiologii - Problems of Cryobiology and Cryomedicine. 2012; 22(2):118-25. [in Ukrainian]

24. Sethe S, Scutt A, Stolzing A, et al. Aging of mesenchymal stem cells. Ageing Res Rev. 2006; 5(1):91-116.

25. Haack-Sørensen M, Ekblond A, Kastrup J. Cryopreservation and Revival of Human Mesenchymal Stromal Cells. Methods Mol Biol. 2016; 1416:357-74.

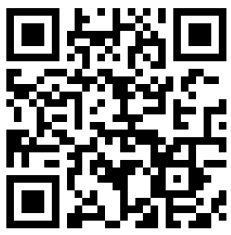

The authors indicate no potential conflicts of interest.

Received: October 04, 2016

Accepted: November 29, 2016

The study was performed with support from the target complex multidisciplinary program of scientific research of NAS of Ukraine «Molecular and cellular biotechnology for medicine, industry and agriculture» the contract number 2.2.6.94. 